\title{
Animal Species Code
}

National Cancer Institute

\section{Source}

National Cancer Institute. Animal Species Code. NCI Thesaurus. Code C93727.

A coded value specifying one of the basic units of biological classification and taxonomic rank that specifies a group of organisms that share similar characteristics and can interbreed with one another to produce fertile offspring. 